\title{
ABRASÃO-CORROSÃO EM CORPOS MOEDORES NA MOAGEM DE MINÉRIO DE FERRO*
}

\author{
Camila Peres Massola ${ }^{1}$ \\ Célia Aparecida Lino dos Santos² \\ Eduardo Albertin ${ }^{3}$ \\ Arthur Pinto Chaves ${ }^{4}$
}

\section{Resumo}

Este trabalho avaliou o efeito da corrosão no desgaste de bolas de aço e de ferro fundido branco de alto cromo durante a moagem de minério de ferro, através de ensaios eletroquímicos e de desgaste em moinho de laboratório. Foi feita uma alteração no modo tradicional de realização do ensaio de polarização potenciodinâmica, utilizando polpa de minério de ferro a $70 \%$ de sólidos (em peso) no eletrólito. As curvas de polarização obtidas foram compatíveis com os resultados de desgaste, de modo que as curvas correspondentes aos metais na condição mais ativa estavam associadas às menores taxas de desgaste nos ensaios de moagem em laboratório, demonstrando que os ensaios de polarização realizados podem ser utilizados como indicativo do comportamento do metal na moagem de minério de ferro. Verificou-se que, nas condições avaliadas, o efeito da corrosão não foi significativo no desgaste dos corpos moedores, tanto de aço quanto de FFBAC.

Palavras-chave: Cominuição; Corpos moedores; Desgaste; Corrosão.

\section{ABRASION-CORROSION OF GRINDING MEDIA IN THE COMMINUTION OF IRON ORE}

\section{Abstract}

This work analyzed the effect of corrosion on the wear of balls made of steel and high chromium cast iron, while grinding iron ore, by means of electrochemical tests and wear tests conducted in a laboratory mill. A modification of the traditional potenciodynamic polarization test is proposed, using iron ore slurry at $70 \% \mathrm{w} / \mathrm{w}$ as an electrolyte. The results of the polarization curves were compatible with those from the wear tests, as the curves corresponding to the condition in which the metal showed the more active behavior were associated to the lower wear rates in the wear tests, suggesting that the modified polarization tests can be used as an indicative of the metal alloy behavior while grinding iron ore. The effect of corrosion was not significant in the wear of both the types of balls tested.

Keywords: Comminution; Grinding media; Wear; Corrosion.

1 Eng. de Minas, Dra. em Engenharia Mineral, Pesquisadora, Laboratório de Processos Metalúrgicos, Instituto de Pesquisas Tecnológicas do Estado de São Paulo, São Paulo, SP, Brasil.

2 Bacharel em Química, Dra. em Química (Físico-Química), Pesquisadora, Laboratório de Corrosão e Proteção, Instituto de Pesquisas Tecnológicas do Estado de São Paulo, São Paulo, SP, Brasil.

3 Eng. Metalurgista, Dr. em Engenharia Metalúrgica, Pesquisador, Laboratório de Processos Metalúrgicos, Instituto de Pesquisas Tecnológicas do Estado de São Paulo, São Paulo, SP, Brasil.

4 Eng. Metalurgista, Dr em Engenharia Mineral, Prof. Dr., Departamento de Engenharia de Minas e de Petróleo, Escola Politécnica, Universidade de São Paulo, São Paulo, SP, Brasil. 


\section{INTRODUÇÃO}

A indústria mineral depende das operações de cominuição para promover a liberação dos grãos minerais, e certamente se trata de uma etapa caracterizada pelo considerável consumo de energia, podendo alcançar até $75 \%$ da energia elétrica total consumida numa usina de concentração [1]. Outro item de custo significativo na moagem é o desgaste de corpos moedores, que pode chegar a até $50 \%$ dos custos referentes à cominuição e a $25 \%$ dos custos de operação de uma usina de beneficiamento mineral.

O desgaste de corpos moedores em processamento a úmido resulta de mecanismos de abrasão, corrosão e impacto, que duram frações de segundo, mas são suficientes para afetar o desgaste das ligas metálicas.

Os corpos moedores, assim como as superfícies dos minerais a serem moídos, estão sendo continuamente expostos durante a operação de moagem, o que dá oportunidade para ocorrência de interações eletroquímicas que se estabelecem entre o meio moedor e os minerais. A interação entre efeitos tribológicos e eletroquímicos leva os materiais a se desgastarem a uma velocidade distinta daquela observada sob condições individuais. A esse fenômeno se denomina tribocorrosão, ou seja, mecanismos de degradação da superfície quando há interação de desgaste mecânico com processos eletroquímicos [2], e normalmente está ligada à sinergia resultante do acoplamento dos efeitos mecânicos e ambientais, embora em alguns casos especiais esse acoplamento possa ser antagônico.

O desgaste total verificado em tribocorrosão pode ser descrito como função da degradação do metal e degradação da partícula [3]. A degradação do metal pode ocorrer devido à remoção de fragmentos por um dos mecanismos de desgaste (adesão, abrasão, fadiga de baixo ciclo) ou por oxidação eletroquímica que ocorre na superfície do metal. Já a degradação da partícula ocorre na região de contato, e inclui a oxidação de fragmentos metálicos removidos da superfície, que podem ser reincorporados à camada de óxido formada sobre o metal, ou podem ser ejetadas do contato, constituindo-se, então, em fragmentos de desgaste. Os autores afirmam que, em princípio, partículas destacadas da superfície do metal podem ser reincorporadas e oxidadas, formando uma camada de óxido compacta e mais grossa. A reincorporação dessas partículas é afetada pela sua capacidade de deformação e por sua adesão ao metal e ambos os fenômenos são influenciados pela natureza do metal e pelos efeitos químicos de superfície. Porém, na presença do filme passivo, a reintegração por recobrimento de partículas destacadas se torna mais difícil e, portanto, o desgaste é maior. Adicionalmente, a corrosão acelerada pelo desgaste contribui significantemente para a degradação dos materiais em potenciais passivos [3].

A literatura propõe ainda alguns modelos que explicariam a interação entre os mecanismos de abrasão e corrosão de corpos moedores durante a moagem de minérios: durante a operação de moagem uma superfície recentemente desgastada (dos corpos moedores) fica exposta à água e ocorre a formação de uma camada de óxido ou de hidróxido para recobrir esta superfície [4]. Células galvânicas locais podem se formar entre os corpos moedores e a polpa, o que é facilitado na presença de oxigênio [5].

Entretanto, embora a ocorrência do fenômeno de corrosão durante processos de moagem a úmido seja praticamente consenso, sua importância não está bem documentada. Os resultados obtidos por alguns pesquisadores sugerem que a 
corrosão não é apenas importante, como pode ser o mecanismo predominante de remoção de metal durante a moagem a úmido. Em moagem de laboratório em bateladas, a corrosão pode representar entre 25 e $75 \%$ do desgaste de metal dependendo do minério, metal e condições ambientais envolvidos [6].

Portanto, ainda que já haja algum conhecimento acerca dos efeitos individuais das variáveis que afetam o consumo de corpos moedores, o entendimento do seu desgaste é uma tarefa desafiadora, devido ao grande número de variáveis envolvidas e à interação entre elas, além da dificuldade - ou mesmo impossibilidade - de observar diretamente essas variáveis [7]. Além disto, a contribuição relativa de cada um dos mecanismos ainda não está estabelecida [8].

A partir dessas considerações, este trabalho procurou avaliar a influência do desgaste corrosivo no processo de desgaste total de corpos moedores tipo bola, durante a moagem de minério de ferro.

\section{MATERIAIS E MÉTODOS}

O trabalho experimental compreendeu a avaliação do desgaste total dos corpos moedores em ensaios de moagem em planta piloto de laboratório, e a avaliação do comportamento dos corpos moedores frente à corrosão, através de ensaios eletroquímicos para determinação das curvas de polarização dos materiais.

Os corpos moedores constituem-se de ligas de aço $(0,76 \% \mathrm{C}, 0,32 \% \mathrm{C})$ e de ferro fundido branco de alto cromo - FFBAC $(2,22 \% \mathrm{C}, 30,1 \% \mathrm{Cr})$, disponíveis comercialmente. Dos lotes de bolas considerados, cerca de 30 bolas de cada tipo foram amostradas aleatoriamente e receberam uma marcação individual, por eletroerosão, com marcas facilmente reconhecíveis para permitir identificar e recuperar essas bolas dentre as bolas da carga do moinho, permitindo seu acompanhamento durante os ensaios de desgaste.

Anteriormente aos ensaios de desgaste propriamente ditos, foi realizado o run in ou período preliminar de moagem, visando remover heterogeneidades superficiais das bolas decorrentes dos processos de fundição e tratamento térmico, além de remover a estrutura coquilhada presente nas regiões próximas à superfície nas bolas de FFBAC. O run in foi realizado em planta piloto de moagem a úmido, durante $50 \mathrm{~h}$ com areia e $16 \mathrm{~h}$ com minério de ferro, preparando a superfície das bolas para os ensaios de desgaste.

\subsection{Ensaios de Desgaste}

Os ensaios de desgaste foram realizados em planta piloto de moagem, constituída por um moinho Denver (0,4 $\mathrm{m}$ de diâmetro e $0,4 \mathrm{~m}$ de comprimento) com velocidade $53 \mathrm{rpm}(70 \%$ da velocidade crítica), e ciclone para fechamento do circuito e classificação em $325 \#$ Tyler $(0,044 \mathrm{~mm})$. A porcentagem de sólidos da polpa na saída do moinho foi mantida em $75 \%$.

Um ensaio típico de desgaste constitui-se de períodos de moagem em que bolas marcadas e não marcadas são carregadas ao moinho, efetuando-se a pesagem individual das bolas marcadas previamente ao carregamento e após um determinado período de moagem. A perda de massa das bolas pode ser convertida em variação de diâmetro (de acordo com a teoria linear do desgaste), e a inclinação da reta "variação do diâmetro em função do tempo" é numericamente igual à velocidade de desgaste do corpo moedor, expressa em $\mu \mathrm{m} / \mathrm{h}$.

O desgaste das bolas de FFBAC e de aço em planta piloto foi realizado com a polpa 
em duas condições: no pH natural da polpa de minério de ferro (ao redor de 8,0), e em pH ácido, $(5,0)$, conseguido com a adição de $\mathrm{HCl}$ ao sistema. Essa condição foi avaliada para verificar o efeito do $\mathrm{pH}$ da polpa no desgaste das bolas, pois condições ácidas poderiam favorecer a corrosão.

$\mathrm{Em}$ ambas as condições, foram realizados ensaios de desgaste com a carga do moinho constituída totalmente por um único tipo de bola, FFBAC ou aço.

\subsection{Ensaios Eletroquímicos}

Os ensaios referentes à avaliação da corrosão foram realizados em um potenciostato Solartron modelo 1287 , com interface para o microcomputador e a aquisição dos dados feita pelo programa CorrWare e CorrView.

Os corpos de prova de aço e de FFBAC foram embutidos individualmente em resina baquelite e o acabamento superficial dos corpos de prova foi feito por lixamento com lixas d'água até grana 1.200 , seguido de polimento com pasta de diamante de $1,0 \mu \mathrm{m}$.

Cada um dos ensaios eletroquímicos consistiu em realizar levantamento do potencial E em função do tempo durante 60 minutos, determinando o potencial de circuito aberto (PCA). Decorrido esse período, foi iniciada a polarização anódica potenciodinâmica, varrendo os potenciais de $-0,03 \mathrm{~V}$ em relação ao potencial de circuito aberto até $+0,70 \mathrm{~V}$ em relação ao eletrodo de referência (eletrodo de calomelano saturado). Ao final da varredura, o sistema foi desligado e o corpo de prova foi removido do sistema, enxaguado com água destilada e etanol P.A., e seco com ar quente.

Embora os ensaios clássicos eletroquímicos considerem apenas a utilização de eletrólitos na ausência de particulados, para a finalidade deste trabalho foi absolutamente necessário realizar os ensaios utilizando polpa de minério de ferro como eletrólito, com $70 \%$ de sólidos em peso, para observar o comportamento eletroquímico do FFBAC e do aço em condições mais próximas às observadas num moinho - ainda que não sejam exatamente as mesmas. Visando à agitação da polpa, optou-se pela utilização do eletrodo de disco rotativo, à velocidade de $1.500 \mathrm{rpm}$, de modo que as partículas minerais em suspensão também poderiam influir de alguma forma na abrasão dos corpos de prova. A agitação imposta à polpa pelo eletrodo também força a entrada de oxigênio na polpa e, desse modo, a cinética da corrosão (ou da passivação) não ficam limitadas à disponibilidade de oxigênio. Os ensaios de polarização realizados estão apresentados na Tabela 1.

Tabela 1. Condições de realização dos ensaios eletroquímicos

\begin{tabular}{|c|c|c|c|}
\hline Tipo de eletrodo & Material & Eletrólito & $\mathrm{pH}$ \\
\hline \multirow{7}{*}{$\begin{array}{c}\text { Eletrodo de disco } \\
\text { rotativo ( } 1.500 \\
\text { rpm) }\end{array}$} & \multirow{3}{*}{ Aço } & Polpa minério de ferro & 5 \\
\hline & & $(70 \% \mathrm{w} / \mathrm{w})$ & 8 \\
\hline & & Áqua & 5 \\
\hline & \multirow{4}{*}{ FFBAC } & & 5 \\
\hline & & $(70 \% \mathrm{w} / \mathrm{w})$ & 8 \\
\hline & & & 5 \\
\hline & & Agua & 8 \\
\hline
\end{tabular}




\section{RESULTADOS E DISCUSSÃO}

\subsection{Ensaios de Desgaste}

As velocidades de desgaste, determinadas para o aço e para o FFBAC nas duas condições de processo consideradas ( $\mathrm{pH} 5$ e pH 8), são apresentadas na Figura 1.

Nas duas condições, o aço desgasta a uma velocidade maior que o FFBAC, o que já era esperado, considerando os resultados reportados na literatura, assim como a prática industrial. Porém, a velocidade de desgaste do aço aumenta quando se passa do $\mathrm{pH} 8$ para $\mathrm{pH} 5$, enquanto que, para o FFBAC, ocorre o contrário: em $\mathrm{pH} 8$, a velocidade de desgaste do FFBAC é maior que em pH 5.

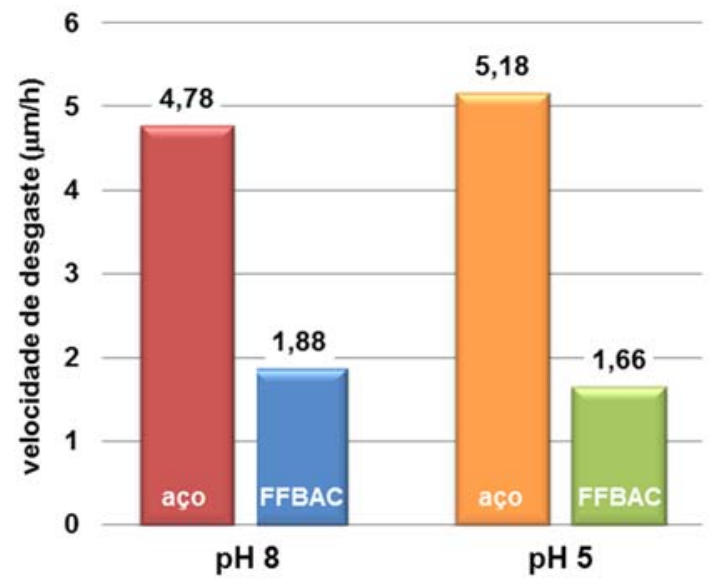

Figura 1. Velocidades de desgaste do aço e do FFBAC.

\subsection{Ensaios Eletroquímicos}

\subsubsection{Determinação do potencial de circuito aberto (OCP)}

As curvas $\mathrm{E} \times \mathrm{t}$ para o aço (Figura 2) mostram que, quando colocado em contato com o mesmo tipo de eletrólito (água destilada ou polpa de minério), o metal assume o mesmo valor de potencial, independente do $\mathrm{pH}$. Quando se consideram os ensaios realizados em água destilada, nos primeiros $60 \mathrm{~s}$ se observa uma queda de potencial, mais acentuada em pH 5. Tal diminuição no potencial pode ser interpretada como a dissolução de uma camada de óxido pré-existente sobre a superfície do corpo de prova, formada espontaneamente em contato com o ar. A partir dos $60 \mathrm{~s}$, porém, ambas as curvas indicam aumento no valor do potencial para valores cada vez mais positivos, o que pode indicar um possível recobrimento da superfície por camada de óxido; e, embora as curvas apresentem inclinações diferentes, ambas convergem para o mesmo valor de potencial (aproximadamente $0,17 \mathrm{~V})$.

Embora a presença do minério de ferro torne o metal mais ativo, ou seja, diminua o valor de potencial do aço em relação às curvas $\mathrm{E} x \mathrm{t}$ em água destilada no mesmo $\mathrm{pH}$, o comportamento das curvas na presença da polpa é distinto nos valores de $\mathrm{pH}$ considerados. Em polpa no $\mathrm{pH} \mathrm{5,} \mathrm{nos} \mathrm{primeiros} 60$ segundos há um aumento do valor de potencial (formação de camada de óxido), seguido por ligeira queda e novo aumento, com tendência de estabilização em torno de $-0,30 \mathrm{~V}$ aos $3.000 \mathrm{~s}$. Em pH 8 , a diminuição do potencial é constante até os $2.000 \mathrm{~s}$, quando então o potencial se estabiliza para valores em torno de $-0,45 \mathrm{~V}$. O comportamento distinto das curvas 
E x t em polpa em diferentes pHs sugere que, nessas condições, o óxido formado sobre a superfície é diferente.

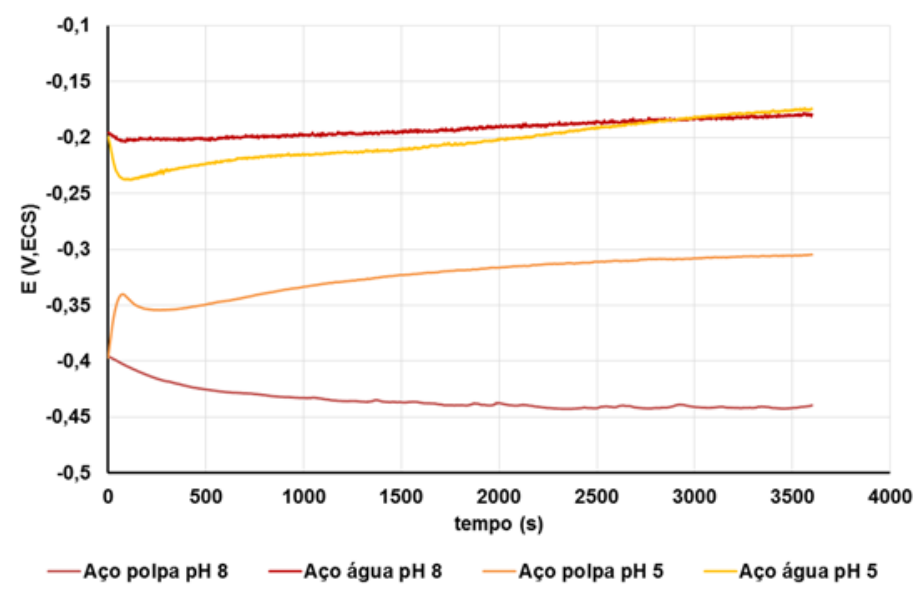

Figura 2. Variação do potencial do aço ao longo do tempo.

Já as curvas E x t para o FFBAC (Figura 3) apresentam comportamentos distintos nas quatro condições avaliadas.

Cada curva parte de um potencial diferente, e todas, à exceção daquela obtida em polpa com pH 8, apresentam uma queda de potencial antes da estabilização, que ocorre rapidamente (antes dos primeiros 10 minutos) em todos os casos. Essa queda é um indicativo da dissolução de uma camada de óxido que possa ter se formado espontaneamente sobre a superfície metálica, pelo contato com o ar; possivelmente é um ataque da camada passiva, cuja recomposição é denotada pela estabilização dos valores de potencial. Na polpa em $\mathrm{pH}$ 8, a suave elevação da curva indica a formação de uma camada de óxido sobre a superfície do eletrodo de trabalho que, novamente, pode ser creditado à formação de camada passiva conforme os motivos anteriormente explicados.

À semelhança do que foi verificado para o aço, a adição de minério diminui o valor de potencial em relação às curvas referentes ao eletrólito água destilada, o que pode ser atribuído aos danos mecânicos à camada passiva promovidos pela agitação da polpa. Para o FFBAC, o menor potencial é alcançado em polpa no $\mathrm{pH} 5$, situação em que o metal está mais ativo.

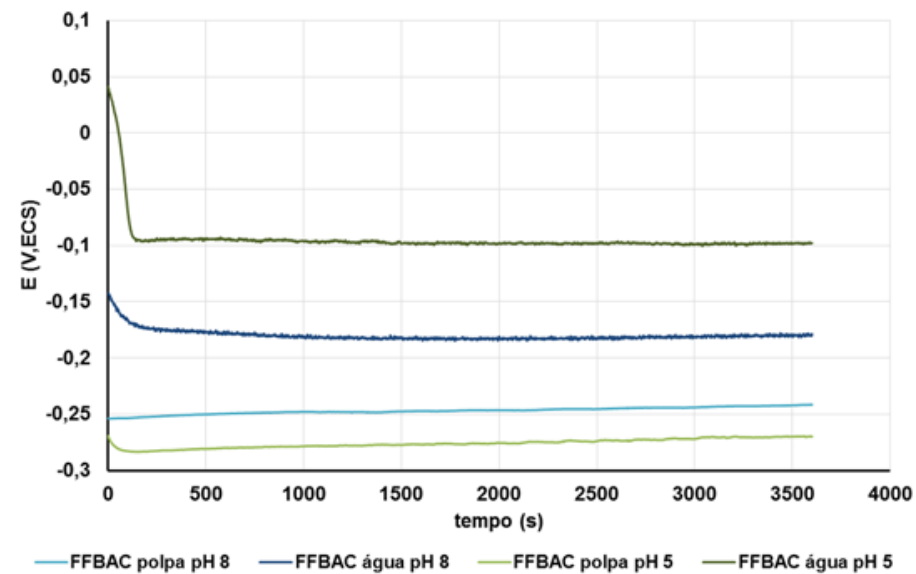

Figura 3. Variação do potencial do FFBAC ao longo do tempo. 


\subsubsection{Curvas de polarização}

A polarização foi realizada imediatamente após a determinação do potencial de circuito aberto.

As curvas de polarização para o aço (Figura 4) mostram que, no eletrólito de suporte (água destilada), o comportamento desse material independe do $\mathrm{pH}$ : em $\mathrm{pH} 5 \mathrm{e} \mathrm{pH}$ 8 , as duas curvas são praticamente idênticas. Embora a corrente chegue a valores da ordem de $10^{-4} \mathrm{~A}$, que já pode ser indicativa de corrosão, tais valores são alcançados apenas em polarizações elevadas. Em baixas polarizações, as correntes são da ordem de $10^{-6} \mathrm{~A}$, sugerindo a passivação do aço (que, para $\mathrm{pH} 8$, já era esperada). $\mathrm{O}$ comportamento idêntico das curvas em $\mathrm{pH} 5$ e 8 , no eletrólito de suporte, pode ser devido à agitação do eletrodo, que força a entrada de ar para o interior da solução. Dessa forma, o eletrólito fica com excesso de oxigênio, condição que favorece o processo tanto de polarização quanto de corrosão, pois não fica limitado à disponibilidade de agente oxidante.

A adição de minério de ferro ao eletrólito de suporte, formando a polpa, provoca o deslocamento das curvas para valores mais baixos de potencial (despolarização), com maior queda no ensaio em $\mathrm{pH}$ 8, e para correntes maiores (da ordem de uma década, alcançando $10^{-3} \mathrm{~A}$ ), pois a presença de sólidos em suspensão continuamente remove a camada passiva que possa estar formada sobre o aço. Em baixas polarizações, as curvas referentes à polpa atingem correntes características de corrosão, da ordem de $10^{-4} \mathrm{~A}$, com correntes ainda mais elevadas para polarizações mais altas.

Não se pode afirmar que o aço em polpa no $\mathrm{pH} 5$ tenha comportamento à corrosão destacadamente melhor que em $\mathrm{pH} 8$, visto que, para baixas polarizações, as curvas nessas duas situações são muito semelhantes, estando deslocadas apenas pelo OCP.

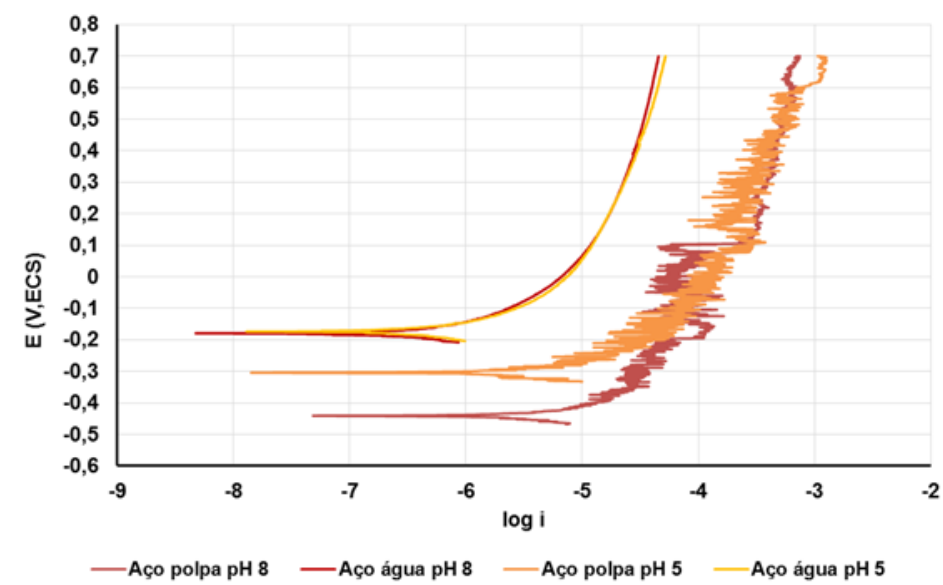

Figura 4. Curvas de polarização para o aço

A observação dos corpos de prova após o levantamento das curvas de polarização mostrou que, nos ensaios realizados no eletrólito de suporte, não houve alteração da superfície do aço perceptível a olho desarmado. Porém, nos ensaios realizados em polpa, em ambos os valores de $\mathrm{pH}$, foi possível verificar a presença de uma camada de óxido de coloração vermelho-alaranjada, desenhando um padrão congruente com o vórtice do fluxo de polpa provocado pela rotação do eletrodo.

No ensaio com polpa em pH 5 , nas regiões em que não houve aderência do minério, verificou-se a presença de inúmeros pontos oxidados, recobrindo todo o corpo de prova, e que pode ser uma camada de produto de corrosão. Em pH 8, ao contrário, 
a presença de algumas regiões com brilho metálico era claramente perceptível, indicando a proteção do aço, conforme pode ser visto na Figura 5, que apresenta a aparência dos substratos após a polarização.

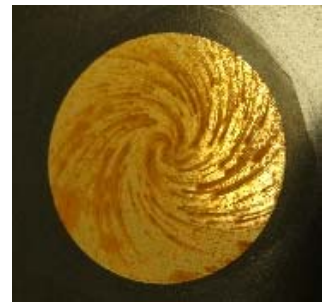

A - polpa pH 5

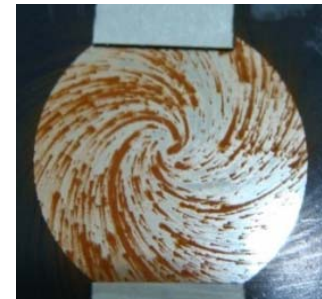

$\mathrm{B}$ - polpa $\mathrm{pH} 8$

Figura 5. Aparência dos corpos de prova de aço após os ensaios de polarização em polpa de minério

A Figura 6 apresenta as curvas de polarização para o FFBAC. No eletrólito de suporte, o potencial de circuito aberto do FFBAC é maior em $\mathrm{pH} 5$ que em $\mathrm{pH} 8$, porém, ambas as curvas atingem densidade de corrente da mesma ordem de grandeza $\left(10^{-7} \mathrm{~A}\right)$, considerada baixa e não indicativa de corrosão. Assim como para o aço, a adição de minério para formar a polpa despolariza as curvas, pois os sólidos em suspensão provocam danos mecânicos à camada passiva. Porém, despolarização é mais significativa em pH 5 que em pH 8.

A natureza das curvas de polarização para o FFBAC sugere que o material passivou em todas as condições de ensaio, verificado pelo trecho aproximadamente vertical das curvas de polarização, e pelas baixas densidades de corrente (da ordem de 10${ }^{6} \mathrm{~A} / \mathrm{cm}^{2}$ ). Entretanto, nas duas curvas referentes aos ensaios com polpa de minério de ferro, esse trecho apresenta uma inclinação positiva, ainda que bastante suave. Isso pode ser creditado ao fato de que as partículas minerais em suspensão são capazes de romper o filme passivo, mas que se recompõe muito rapidamente, devido ao elevado teor de cromo da liga metálica. Na condição em polpa no pH 5, o filme passivo sobre o FFBAC é rompido para polarizações superiores a $0,2 \mathrm{~V}$, ECS. Ao final dos ensaios, não foram identificadas quaisquer alterações significativas das superfícies do FFBAC a olho desarmado; apenas na condição polpa pH 5 surgiram algumas nódoas discretas na superfície metálica, mas que não foi possível captar com a câmera fotográfica.

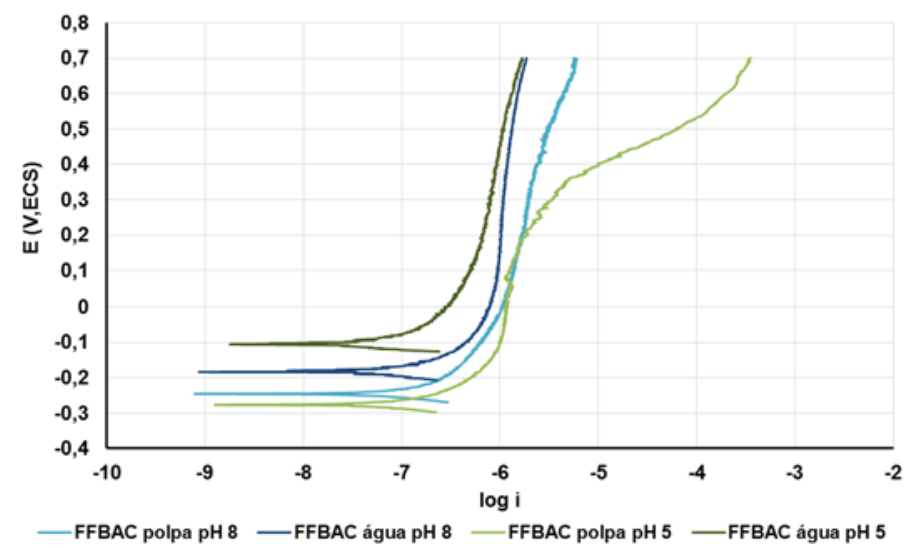

Figura 6. Curvas de polarização para o FFBAC 


\subsection{Discussão dos Resultados dos Ensaios de Desgaste e Eletroquímicos}

Através da comparação das curvas de polarização dos materiais, confirma-se que o aço é um material mais susceptível à corrosão que o FFBAC em ambas as situações, atingindo valores de correntes maiores que este. $\mathrm{Em} \mathrm{pH} \mathrm{8,} \mathrm{o} \mathrm{aço} \mathrm{é}$ espontaneamente mais ativo que o FFBAC, enquanto que no $\mathrm{pH} 5$ a atividade é semelhante, mas com correntes diferentes por duas ordens de grandeza. Ou seja, na polpa em pH 8 o aço está mais sujeito à corrosão que em pH 5.

Conforme foi verificado nos ensaios eletroquímicos, as curvas de polarização em $\mathrm{pH}$ 5 e pH 8 do aço apresentam o mesmo comportamento, indicativo de corrosão, estando deslocadas pelo potencial de circuito aberto. Em outras palavras, apesar da tendência à corrosão, em pH 80 aço está menos nobre. Em pH 5, a velocidade de desgaste é apenas $8,4 \%$ superior à velocidade de desgaste desse material em $\mathrm{pH} 8$. Isto porque a ação da abrasão da polpa de minério durante a moagem se sobrepõe a qualquer diferença no comportamento à corrosão que o aço possa apresentar, possivelmente devido à dureza da bola e baixa aderência do produto de corrosão do aço ao substrato. Considerando a teoria de Mischler et al. (2001), a corrosão acelerada pela abrasão é mais significativa em pH 5 que em pH 8, para o aço.

No caso do FFBAC, a maior velocidade de desgaste foi verificada em $\mathrm{pH} 8$. Embora em ambas as condições de pH o FFBAC esteja passivado, em pH 8 o metal está menos ativo que em $\mathrm{pH} 5$. É provável que, em pH 5, a natureza da camada de óxido formada permita uma maior reincorporação de partículas destacadas da superfície da bola por desgaste, comparando ao $\mathrm{pH} 8$, se refletindo em uma velocidade de desgaste $40 \%$ menor. Assim, há indícios de que a diminuição do pH contribui para a diminuição da degradação do FFBAC, corroborando o que foi proposto por Mischler et al. (2001), de que a presença do filme passivo sobre a superfície metálica acelera o desgaste.

\section{CONCLUSÃO}

Este trabalho buscou identificar o papel da corrosão no mecanismo de desgaste de bolas de aço e de FFBAC durante a moagem de minério de ferro. A metodologia utilizada para o levantamento das curvas de polarização não é tradicional, pois se considerou a adição de partículas de minério ao eletrólito, formando uma polpa com $70 \%$ de sólidos em peso e que foi movimentada pela rotação do eletrodo a 1.500 rpm. Desta forma, do ponto de vista eletroquímico, os ensaios realizados deste modo foram consistentes, já que a adição de minério de ferro despolarizou as curvas, devido à ação mecânica das partículas minerais sobre a superfície dos eletrodos de trabalho.

As curvas de polarização referentes às condições aço em polpa com pH 8 e FFBAC em polpa com pH 5 indicam se tratar das condições em que a superfície dos metais está menos nobre, ou seja, mais favoráveis à corrosão. Porém, essas também foram as condições em que se verificaram as menores velocidades de desgaste para o aço e para o FFBAC, determinadas nos ensaios de moagem em planta piloto. Quanto mais ativo o metal, menor é o desgaste total do material, numa situação de tribocorrosão.

Considera-se, portanto, que os ensaios de polarização, tal como realizados, forneceram indícios satisfatórios do comportamento do metal imerso numa polpa de minério, coerentes com as velocidades de desgaste determinadas nos ensaios piloto de moagem: o metal que apresenta o comportamento mais ativo é o que apresenta 
também a menor velocidade de desgaste. Porém, não se descarta a realização dos ensaios de desgaste em planta piloto, pois é uma ferramenta valiosa para avaliar o desgaste de ligas metálicas num sistema tão complexo quanto a moagem a úmido de minérios em moinhos tubulares.

No que se refere ao efeito da corrosão sobre as bolas, nas condições avaliadas, os resultados obtidos mostram que, para as bolas de aço, a ação da abrasão da polpa de minério durante a moagem se sobrepõe a qualquer diferença no comportamento à corrosão que o aço possa apresentar, possivelmente devido à dureza da bola e à baixa aderência do produto de corrosão do aço ao substrato, ou seja, a corrosão não representa parcela significativa no desgaste das bolas de aço. Para as bolas de FFBAC, a formação da camada passiva influiu efetivamente na velocidade de desgaste; menor em pH 5 que em pH 8. Como em ambas as condições o FFBAC está passivado, isto pode ser devido a alguma alteração mecânica da superfície do metal, decorrente de diferenças entre os filmes passivos formados nas duas condições de processo, já que as condições abrasivas foram mantidas. Além disso, considerando que as curvas de polarização mostram que em pH 5 o FFBAC está mais ativo que em $\mathrm{pH} 8$, a menor velocidade de desgaste observada na primeira condição sugere que, ao contrário do que se poderia esperar, os efeitos da abrasão e da corrosão foram antagônicos, ou seja, não ocorreu sinergismo entre os dois mecanismos de desgaste.

\section{REFERÊNCIAS}

1 MUSA, F.; MORRISON, R. A more sustainable approach to assessing comminution efficiency. Minerals Engineering, v. 22, p. 593-601, 2009.

2 WOOD, R.J.K. Tribocorrosion. In: COTTIS, R.A. et al.. (Ed.). Shreir's corrosion. 4th. ed. Amsterdam; London: Elsevier, 2010. v. 2, p. 1007-1050.

3 MISCHLER, S.; SPIEGEL, A.; STEMP, M.; LANDOLT, D. Influence of passivity on the tribocorrosion of carbon steel in aqueous solutions. Wear, v. 251, p. 1295-1307, 2001.

4 SALASI, M.; STACHOWIAK, G.B.; STACHOWIAK, G.W. Three-body tribocorrosion of high-chromium cast irons in neutral and alkaline environments. Wear, v. 271, p. 13851396, 2011.

5 IWASAKI, I.; POZZO, R.L.; NATARAJAN, K.A.; ADAM, K.; ORLICH, J.N. Nature of corrosive and abrasive wear in ball mill grinding. International Journal of Mineral Processing, v. 22, p. 345-360, 1988.

6 CHENJE, T.W.; SIMBI, D.J.; NAVARA, E. The role of corrosive wear during laboratory milling. Minerals Engineering, v. 16, p. 619-624, 2003.

7 ALDRICH, C. Comsumption of steel grinding media in mills: a review. Minerals Engineering, v. 49, p. 77-91, 2013.

8 RADZISZEWSKI, P. Exploring total media wear. Minerals Engineering, v. 15, p. 10731087, 2002. 